\title{
Intensive Care Units and Operating Rooms Bacterial Load and Antibiotic Susceptibility Pattern
}

\author{
Mengistu Hailemariam ${ }^{1,}$, Mesfin Worku ${ }^{1}$, Elshadie Azerefegne ${ }^{2}$ \\ ${ }^{1}$ Department of Medical Laboratory Sciences, College of Medicine and Health Sciences, Hawassa University, Hawassa, Ethiopia \\ ${ }^{2}$ Medical Laboratory Unit, Hawassa University Referral Hospital, Hawassa, Ethiopia
}

Email address:

mengamariam@yahoo.com (M. Hailemariam)

${ }^{*}$ Corresponding author

\section{To cite this article:}

Mengistu Hailemariam, Mesfin Worku, Elshadie Azerefegne. Intensive Care Units and Operating Rooms Bacterial Load and Antibiotic Susceptibility Pattern. Journal of Surgery. Vol. 4, No. 2, 2016, pp. 60-64. doi: 10.11648/j.js.20160402.21

Received: August 17, 2015; Accepted: August 26, 2015; Published: May 30, 2016

\begin{abstract}
Introduction. The indoor air environment can potentially place patients at a greater risk because enclosed spaces can confine aerosols and allow them to build up to infectious levels as a result, this study intended to determine the bacterial load and antibiotic susceptibility pattern in operating theater (OR) and intensive care unit (ICU) at Hawassa University Referral Hospital. Methods. A cross sectional study was conducted to measure indoor air microbial quality from Nov 2014 to February 2015 on 120 air samples collected from selected sites in 15 rounds using purposive sampling technique by Settle Plate Method (Passive Air Sampling following 1/1/1 Schedule). Sample processing and antimicrobial susceptibility testing was done using standard microbiological methods. The data was analyzed using SPSS version 16.0 and was inferred based on baseline values recommended by Fisher. Result. The mean bacterial load of ICU $454.2 \mathrm{CFU} / \mathrm{dm}^{2}$ was recorded. Likewise, at OR during active, $87.27 \mathrm{CFU} / \mathrm{dm}^{2}$ and $13.12 / \mathrm{CFU} / \mathrm{dm}^{2}$ during passive were recorded. Compared to the standard set by Fisher, the ICU and OR while at passive were higher than the acceptable limit. Among the isolated six bacteria, S. aurous $36(30 \%)$ was the predominant species in both OR and ICU were as p. auriginosa $16(26.7 \%)$ was the second prevailing isolates at ICU. S. aureus was highly resistant to penicillin, tetracycline $86.1 \%, 72.2 \%$ respectively were as $P$. auriginosa showed low level resistance to Ciprofloxacin (22.2\%), Cotrimoxazole (27.7\%) and Ceftriaxon (16.7\%). Conclusion. This finding indicates that resistant isolates for the commonly used drugs and high bacterial load of indoor air judges the risk factor for SSI as well more risking ICU patients. Hence adequate attention should be given to maintenance of proper hygiene in the ICU and OR environments since it is well known those patients are highly susceptible to microbial infection.
\end{abstract}

Keywords: Indoor Air, Intensive Care Unit, OR, Southern Ethiopia

\section{Introduction}

Microbial contamination of indoor hospital, especially in an operating theatre and other specialized units had continued to increase prevalence of nosocomial infections. With resultant effect of high morbidity and mortality rate among patient admitted for post-operative surgery, patients $[1,2]$.

Enclosed air environment can potentially place patients at a greater risk because enclosed spaces can confine aerosols and allow them to build up to infectious levels [3]. Therefore Infection prevention and patient safety should be at the great concern of hospital management [4]. Patients admitted to intensive care units, in particular, often become colonized with resistant organisms and may serve as the focus for hospital-wide bacterial resistance [5]. The high prevalence of resistance in intensive care units (ICUs) has been attributed to the severity of illness of the patients, prolonged hospital stays, and the widespread use of invasive devices and broad spectrum antibiotics. The rate of hospital acquired infection in critically ill patients is about $20 \%$, depending on the type of admission diagnosis and underlying conditions predisposing to microbial colonization and infection [6].

Microorganisms were transmitted to the patients by the contaminated hands of healthcare workers. OR and ICU are the places that need the maximum cleanliness standards, also the same necessities for the health workers [4]. The significance of the estimation of the indoor bacterial load can 
be used as an index for the cleanliness of the environment as well as an index they bear in relation to human health and as source of hospital-acquired infections.

\section{Materials and Methods}

\subsection{Study Area}

The study was conducted at Hawassa Referral Hospital, Hawassa, Southern Ethiopia. Hawassa, the capital of SNNPR and it is located $275 \mathrm{~km}$ from the capital city of Ethiopia, Addis Ababa. The total population of Hawassa town is 130,579 with one to one male to female ratio. Hawassa Referral Hospital was inaugurated in November, 2005; it has 850 beds and serves about 12 million people. The hospital has about 300 daily outpatient visits. It has one OR with 4 separate space and one ICU with a total of 16 beds.

\subsection{Study Design and Sampling}

A descriptive cross-sectional study was conducted between Nov 2014 and February 2015 in Hawassa Referral Hospital. The air samples collected twice per day in two representative section in each site during active and passive in OR and at morning and afternoon in ICU over a period of 15 weeks. Air samples were collected using Settle Plate or Passive Air Sampling method following 1/1/1 schedule (a nine $\mathrm{cm}$ in diameter sterile Petri dish with 5\% Sheep's blood agar was left open to the air for an hour, a meter above the floor and a meter from the wall) [7]. During air sampling sterile gloves, mouth masks and protective gown was worn to prevent self contamination of the 5\% Sheep's blood agar plate (Oxoid, UK).

The air samples in ORs were collected during both active and passive whereas samples from ICU was collected in the morning and afternoon in each round per week. Then, blood agar plates was transported to the microbiology laboratory and incubated aerobically for 24 hours at $37^{\circ} \mathrm{C}$. The total number of colony forming units (CFU) was enumerated using colony counter and results were expressed in $\mathrm{CFU} / \mathrm{dm}^{2}$ [8]. The colonies were assessed further using the biochemical tests following standard bacteriological techniques to isolate species [9].

The antimicrobial susceptibility testing was done on Mueller-Hinton agar (Oxoid, UK) for every potential pathogenic bacteria isolates with 12 antibiotics each by KirbyBauer disk diffusion method matching the test organism to 0.5 McFarland turbidity standards. Then, the susceptibility result was interpreted according to the principles established by Clinical and Laboratory Standards Institute (CLSI) by measuring the zone diameter of inhibition [10].

Reference strains $S$. aureus (ATCC 25923); E. coli (ATCC 25922) and $P$. aeruginosa (ATCC 27853) used as a quality control for culture and susceptibility testing throughout the study.

All data was analyzed using Statistical package for Social Sciences (SPSS) version 16.0 and Microsoft Office Excel. Results were interpreted according to baseline values suggested by Fisher [7, 11] and values of $p<0.05$ was considered as statistically significant. The official permission and approval was obtained from the Department of Medical Laboratory Sciences, Hawassa University.

\section{Results}

A total of 120 air samples were collected, twice per day in two representative sections in each site during active and passive in OR also at morning and afternoon in ICU over a period of 15 weeks. The finding showed that ICU had the highest bacterial counts $654 \mathrm{CFU} / \mathrm{dm}^{2}$ and the OR had the lowest bacterial count $6 \mathrm{CFU} / \mathrm{dm}^{2}$ during active period. The mean bacterial load of OR during active, $87.27 \mathrm{CFU} / \mathrm{dm}^{2}$ and during passive $13.12 / \mathrm{CFU} / \mathrm{dm}^{2}$ were recorded. According to Fisher's index of microbial air contamination [7], air microbial count of OR at rest and in activity must not exceed 9.0 and 91.0 CFU/ $\mathrm{dm}^{2}$ respectively (Table 1).

Table 1. Mean bacterial counts of air samples against the standard in HURH.

\begin{tabular}{|c|c|c|c|c|c|}
\hline \multirow{2}{*}{ SITE } & & \multirow{2}{*}{ Aerobic CFU/dm²; No. (mean value) } & \multicolumn{3}{|c|}{ Standard $\left(\mathrm{CFU} / \mathrm{dm}^{2}\right)[5]^{*}$} \\
\hline & & & OPTIMAL & ACCEPTABLE & UNACCEPTABLE \\
\hline \multirow{2}{*}{ OR } & Active & $30(87.27)$ & $0-60$ & $61-90$ & $>91$ \\
\hline & passive & $30(13.12)$ & $0-4$ & $5-8$ & $>9$ \\
\hline \multirow{3}{*}{ ICU } & Morning & $30(474.26)$ & \multirow{3}{*}{$0-250$} & \multirow{3}{*}{$251-450$} & \multirow{3}{*}{$>450$} \\
\hline & Afternoon & $30(434.2)$ & & & \\
\hline & Total & $60(454.23)$ & & & \\
\hline
\end{tabular}

*According to Fisher's index of microbial air contamination

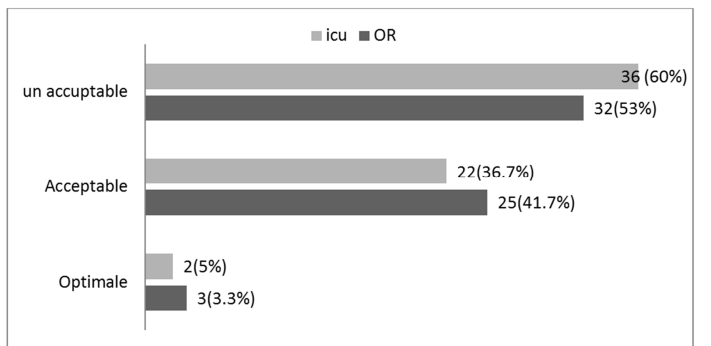

Fig. 1. Proportion of indoor air samples in ICU and OR based on the standard.
Mean aerobic colony count in ICU during morning time of sample collection was $474.3 \mathrm{CFU} / \mathrm{dm}^{2}$ where as in afternoon 434.2 $\mathrm{CFU} / \mathrm{dm}^{2}$. The overall mean colony counts in ICU 454.2 $\mathrm{CFU} / \mathrm{dm}^{2}$ was slightly higher than the sated acceptable limit as shown in the Table-1. On the other hand among the collected samples $60 \%$ from OR and $53 \%$ of ICU were beyond the tolerable limit compared to the standard (Fig. 1).

In regard to timing $45 \%$ of the afternoon samples result compared to $68.3 \%$ of the morning samples were unacceptable which was sign ificantly higher in morning, $\mathrm{p}=0.016$ (Table 3). 
Table 2. Time variation of samples against the standard, HURH.

\begin{tabular}{|c|c|c|c|c|}
\hline & \multicolumn{3}{|c|}{ Number of sample $N=60(\%)$} & \multirow{2}{*}{ p-value } \\
\hline & morning & afternoon & Total\% & \\
\hline OPTIMAL & $3[5]$ & $2[3.3]$ & $5[4.2]$ & \\
\hline ACCEPTABLE & $16[26.7]$ & $31[51.7]$ & $47[39.2]$ & $\mathrm{P}=0.016$ \\
\hline UNACCEPTABL & $41[68.3]$ & $27[45]$ & $68[56.7]$ & \\
\hline Total & $60[100]$ & $60[100]$ & $120[100]$ & \\
\hline
\end{tabular}

Six bacterial isolates were identified. Among these $S$. aurous $36(30 \%)$ and CNS 34 (28.3\%) were the predominant species. Isolates in respect to site, CNS recorded $22(36.7 \%)$ in OR and $12(20 \%)$ in ICU. On the other hand the second prevailing isolates at ICU was p. auriginosa $16(26.7 \%)$ (Figure 2).

The antimicrobial susceptibility patterns of isolates illustrates that $\mathrm{S}$. aureus was highly resistant to penicillin and tetracycline at $86.1 \%$ and $72.2 \%$ respectively. The highest resistance was recorded against Penicillin (80.51\%) followed by Tetracycline (67.23\%) and Erythromycin (60.59\%). However, they were sensitive to Vancomycin (91.7\%) and Clindamycin (75\%) (Table 4). On the other hand the least resistance drugs were Vancomycin (29.05\%), Clindamycin (29.88\%), Ciprofloxacin (30.71\%) and Ceftriaxon (31.54\%).

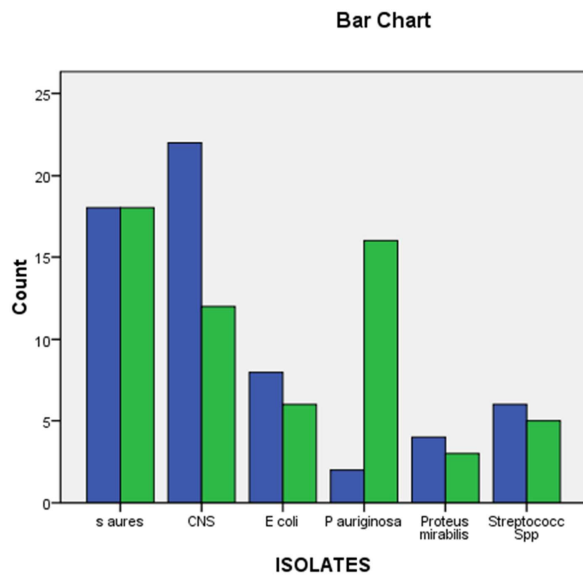

Fig. 2. Bacterial isolate of indoor air by site at HURH.

Table 3. Antimicrobial resistance of bacterial isolates from indoor air of study site.

\begin{tabular}{|c|c|c|c|c|c|c|c|}
\hline \multirow[b]{2}{*}{ Antibiotics tested } & \multicolumn{6}{|c|}{ Number of resistant Isolates (\%) } & \multirow{2}{*}{$\begin{array}{l}\text { Total }(\%) \\
(n=120)\end{array}$} \\
\hline & S. aureus $(n=36)$ & CNS $(n=34)$ & E. coli $(n=14)$ & $\begin{array}{l}\text { P. auriginosa } \\
(n=18)\end{array}$ & $\begin{array}{l}\text { Streptococcus } \\
\operatorname{spp}(n=11)\end{array}$ & $\begin{array}{l}\text { Klebsiellaspp } \\
(n=7)\end{array}$ & \\
\hline Amoxy clavulinic & $20[55.6]$ & $12[35.3]$ & $2[14.2]$ & $5[27.7]$ & $5[45.5]$ & $1[14.3]$ & $45[37.35]$ \\
\hline Ampicillin & $13[36]$ & $14[41.2]$ & $2[14.2]$ & $4[22.2]$ & $3[27.7]$ & $2[28.6]$ & $38[31.54]$ \\
\hline Chloramphenicol & $18[50]$ & $13[38.2]$ & $3[21.4]$ & $5[27.7]$ & $5[45.5]$ & $2[28.6]$ & $46[38.18]$ \\
\hline Clindamycin & $9[25]$ & $14[41.2]$ & $4[28.4]$ & $5[27.7]$ & $3[27.7]$ & $1[14.3]$ & $36[29.88]$ \\
\hline Erythromycin & $33[47.2]$ & $19[55.8]$ & $5[35.7]$ & $7[38.9]$ & $7[63.6]$ & $2[28.6]$ & $73[60.59]$ \\
\hline Cotrimox azole & $16[44.4]$ & $14[41.2]$ & $2[14.2]$ & $5[27.7]$ & $4[36.4]$ & $2[28.6]$ & $41[34.17]$ \\
\hline Ceftriaxon & $14[38.9]$ & $15[44.1]$ & $2[14.2]$ & $3[16.7]$ & $4[36.4]$ & $0[0]$ & $38[31.54]$ \\
\hline Norfloxacin & $16[44.4]$ & $11[32.4]$ & $2[142]$ & $5[27.7]$ & $3[27.7]$ & $2[28.6]$ & $39[32.37]$ \\
\hline Tetracycline & $26[72.2]$ & $22[64.7]$ & $7[50]$ & $15[83.3]$ & $8[72.2]$ & $3[42.8]$ & $81[67.23]$ \\
\hline Penicillin & $31[86.1]$ & $27[79.5]$ & $10[71.4]$ & $16[88.9]$ & $8[72.2]$ & $5[71.4]$ & $97[80.51]$ \\
\hline Vancomycin & $3[8.3]$ & $1[3]$ & $9[64.3]$ & $16[88.9]$ & $1[9]$ & $5[71.4]$ & $35[29.05]$ \\
\hline
\end{tabular}

\section{Discussion}

The microbial load in hospital indoor air is highly influenced by the number of factors beside with ventilation [4]. Ventilation causes dilution thus reducing the microbial load. So, indoor bacterial load analysis is very important to know the stat of ventilation and cleanness of critical areas within the hospital. As already Saied, microbiological quality of air considered as mirror of the hygienic condition of the ICU and operation theatres.

The mean colony count obtained from ICU 454.2 $\mathrm{CFU} / \mathrm{dm}^{2}$ was slightly higher than the acceptable range set by Fisher [11].This finding goes in line with the study conducted in Gaza [12] which revealed that, the total bacterial count within indoor air in two ICUs ranged from (1170 to 1470) $\mathrm{cfu} / \mathrm{m}^{3}$ (standard is less than $50 \mathrm{cfu} / \mathrm{m}^{3}$ ) our finding was also similar with Venezuelans finding [13]which reported, bacteria in surgical settings were within the "clean" range, in addition study from India [14] observe a significant increased percent of bacterial count in ICU. However, the intensive care unit depicted bacterial contamination. However this studies result was different compared to the findings of the study done in Czech Republic [15] which reported that ICU were in the acceptable rang.

The total concentrations of airborne bacteria in this study exceed the standard set by Fisher of $450 \mathrm{cfu} / \mathrm{dm}^{2}$. The finding shows that the hygienic level of the ICU under investigation is unacceptable. The possible explanation for the increased load of CFU counts might be the human trafficking in these room as HURH is a teaching hospital. Besides, the extent of cleaning and continues follow-up of sterility of critical areas of the hospital might contribute for the undesirable aerobic bacterial load observed in these rooms. 
The mean colony count obtained OR in this study is 13.12 $\mathrm{cfu} / \mathrm{d}^{2}$ during active and $87.27 \mathrm{cfu} / \mathrm{d}^{2}$ at rest time respectively (Table-1). In relation with the standard the OR finding during passive reflect a higher counts above standard. Comparable finding was reported in different area such as study in Northern Ethiopia [16] that reported mean colony count of 91.8 , during activity and $17.2 \mathrm{cfu} / \mathrm{dm}^{2}$ during rest, in addition with study in Jordan [17]. Our finding a beat differ to the findings of the study done in Jimma Ethiopia [18] which reported that ORs were not in the acceptable rang compared to standard set by Fisher both during activity and during passive time.

The highest bacterial populations recorded in the morning samples $38(63.3 \%)$ compared to the $27(45 \%)$ of the afternoon samples were beyond the tolerable limit. which was sign ificantly higher in morning, $\mathrm{p}=0.016$ (Table 2).This result was in line with the finding in Northern Ethiopia [16]. But, disagree with Nigeria [19] in which the highest bacterial population was recorded in the evening between time $5 \mathrm{pm}$ and $6 \mathrm{pm}$ compared to the morning also with Jimma South west Ethiopia finding [18] that reported the colony count sinall ORs except Sterilized cloth store were found to be higher in the afternoon than in the morning.

Six bacteria were isolated from a total of 120 air samples examined. Among these S. aureus $36(30 \%)$ and CNS 34 $(28.3 \%)$ were dominant. The finding mainly in OR was almost comparable with most of the studies else where, like the Venezuela [13], Nigeria, [20]; Jordan, [17], Also study conducted in Nigeria [19] where $S$. aureus was predominant. Which indicates the carrier state of health workers at ICU and OR.

On the other hand the second predominant isolates at ICU was $p$. auriginosa the finding is similar with studies conducted in Indonesia [21], Gaza [1], Czech Republic [15] and Taiwan [22] in which $p$. auriginosa were reported as a major isolate in ICU.

The high level of resistance of $S$. aures and CNS to penicillin and tetracycline found in our study has been widely reported throughout the world, $(16,18,19$ and 23) this might be due to emergence of penicillin resistant beta-lactamase producing strains. The most effective antimicrobials for gram positives was Vancomycin, with are sistance rate of $6.1 \%$, were as Ceftriaxon (12.8\% resistance) was best for gram negative isolates. There least resistance drugs were Vancomycin 35 (29.05\%) and Clindamycin 36 (29.88\%). The possible explanation for this might be these drugs not intensively used and not easily available outside the hospitals. In the other hand penicillin was the highest resistant drug with $97(80.51 \%)$ of resistance. This study's finding was similar with others related study else where $[16,18,21]$.

\section{Conclusion}

In general $60 \%$ of OR and $53 \%$ samples from ICU were under the unsatisfactory level of bacterial load. The finding imply that the high bacterial load of indoor air judges as a risk factor for SSI as well more risking ICU patients since there is a linear relationship between bacteria load in air and consequent bacterial infection rate. The acceptable and optimal CFU, in ICU does not guarantee a clean and healthy environment for the reason that, the airborne microbial concentration and the types could be useful in determining the degree of cleanliness of an environment as well as an index they bear in relation to ICU patients health [24]. Hence adequate attention should be given to maintenance of proper hygiene in the ICU environments since it is well known those patients are highly susceptible to microbial infection. This would be greater extent assist to minimize the patient risk as well as for workers who usually spend worth time in the ICU. Mainly effective approach including restrictive entrance of outdoor aerosols, installing suitable filtration devices improving the hospital infection prevention and patient safety (IPPS) should be strengthen.

\section{Acknowledgement}

We acknowledge the HURH, OR and ICU staffs for their help during sample collection. We are thankful for Hawassa University for financial help of this study.

\section{Authors' Contribution}

Both authors (MH and EA) participated in proposal development, data collection, statistical analysis and manuscript write up.

\section{References}

[1] Napoli C, Marcotrigiano V and Montagna MT. Air sampling procedures to evaluate microbial contamination: A comparison between active and passive methods in operating theaters, BMC Puplic health, 2012, vol 12, pp 594.

[2] De Souza AL, Seguro AC. Gram staining: an unexplored diagnostic tool for diagnosis of meningococcal infection in the developing world. J Emerg Med. 2009; 37(1):83-4.

[3] Landrin A, Bissery A, Kac G. Monitoring air sampling in operating theatres: can particle counting replace microbiological sampling? J Hosp Infect 2005; 61: 27-9.

[4] Griffith CJ, Cooper RA, Gilmore J, Davies C, Lewis M. An evaluation of hospital cleaning regimes and standards. J Hosp Infect., 2000, 45(1), 19-28 [PMID: 10833340].

[5] Archibald L, Phillips L, Monnet D, McGowan JE Jr, Tenover F, Gaynes R. Antimicrobial resistance in isolates from inpatients and outpatients in the United States: increasing importance of the intensive care unit. Clin Infect Dis., 1997, 24(2), 211-5 [PMID: 9114149].

[6] Vincent JL, Bihari DJ, Suter PM, Bruining HA, White J, Nicolas-Chanoin MH, Wolff M, Spencer RC, Hemmer M. The prevalence of nosocomial infection in intensive care units in Europe. JAMA, 1995, 274, 639-44 [PMID: 7637145].

[7] Pasquarella C, Pitzurra O, Savino A (2000). The index of microbialair contamination (review). J Hosp Infect 2000; 46: 24156. 
[8] Andersson AE, Bergh I, Karlsson J, Eriksson BI, Nilsson K (2012). Traffic flow in the operating room. An explorative and descriptive study on air quality during orthopedictraumaim plants surgery. Am. J. Infect. Control40 (8): 750-755.

[9] World Health Organization. Basic laboratory procedures in clinical bacteriology. Geneva. 1991. Available at: http://whqlibdoc. who. int/publications/2003/9241545453.pdf accessed on February 16, 2010.

[10] Clinical Laboratory Standards Institute (2012). Performance standards for antimicrobial susceptibility testing; twentysecond information supplement. CLSI. 3: 1-183.

[11] Fisher G, Fodré S, Nehéz M (1972).Das Ergebnis der Unter suchungen zur Feststellungs von Gesamt keimzahl- Grenz werten in der Luft von Operations raumen. English version can be found on are view article by Pasquarella Cet al Z Ges Hyg 1972; 18: 729-733.

[12] Khalid Khadoura, Samir Afifi, Yousef Aljeesh. Environmental Infection Control in Intensive Care Units at Gaza Governorates: Interventional Study, Journal of Natural Sciences Research Vol. 4, No. 23, pp 156-165, 2014.

[13] Carlos A. Rocha, Náyila A. Báez, Evelys V. Villarroel, Gisela M. Quintero. Study of Bioaerosols in Surgical Theaters and Intensive Care Units from a Public General Hospital The Journal of Bioscience and Medicine 2, 3 (2012).

[14] Deepa S, Abishek MU, Venkatesha D. The air as harbinger of infections in critical care units. Medical Science, 2014, 8(28), $8-13$.

[15] Marie Vackova, Irena Hanovcova, Jan Smetana, Roman Chlibek, Vanda Bostikova, Miroslav Splino. Microbial Air Load at the Transplant Intensive Care Unit, Mil. Med. Sci. Lett. (Voj. Zdrav. Listy) 2011, Vol. 80, P. 52-57.

[16] Tewelde Tesfaye Gebremariam, Kibrom Gebreselassie Desta, Yibrah Berhe Zelelowand Saravanan Muthupandian (2015). Microbial load of operating the atreat Ayder Referral Hospital, Northern Ethiopia African Journal of Microbiology Research; vol 9(9):639-642, 2015.
[17] Qudiesat K., K. Abu-Elteen, A. Elkarmi, M. Hamad and M. Abussaud (2009). Assessment of airborne pathogens in health care settings; African Journal of Microbiology Research Vol. 3 (2) pp. 066-076 February, 2009. Available online http://www.academicjournals.org/ajmr.

[18] Genet C, Kibru G, Tsegaye W (2011). Indoorair bacterial load and an tibioticsus ceptibility pattern ofisolates in operating rooms and surgical wards at Jimma University specialized hospital, southwest Ethiopia. Ethiop. J. Health Sci. 21(1):917.

[19] Ekhaise FO, Isitor EE, Idehen O, Emogbene OA (2010). Air born emicro florain the at mosphere of an hospital environment of University of Benin Teaching Hospital (UBTH), Benin City, Nigeria. World J Agric Sci, 2010; 6:166170 .

[20] Shiaka, G. Peter1 and Yakubu, S (2014). Indoor Airborne Bacterial Concentration of a Private-Owned Hospital Laboratory in Samaru-Zaria Journal of Biology, Agriculture and Healthcare Vol. 4, No. 20, 2014.

[21] Maksum Radji, Siti Fauziah, Nurgani Aribinuko. Antibiotic sensitivity pattern of bacterial pathogens in the intensive care unit of Fatmawati Hospital, Indonesia Asian Pac J Trop Biomed 2011; 1(1): 39-42.

[22] Ping-Yun Huang, Zhi-Yuan Shi, Chi-Hao Chen, Walter Den, Hui-Mei Huang, Jaw-Ji Tsai. Airborne and Surface-Bound Microbial Contamination in Two Intensive Care Units of a Medical Center in Central Taiwan Aerosol and Air Quality Research, 13: 1060-1069, 2013.

[23] AlLaham NA (2012). Distribution and Antimicrobial Resistance Pattern of Bacteria Isolated from Operation The aters at Gaza Strip. J. Al Azhar University-Gaza. 14: 19-34.

[24] Bhatia, L. (2011). Impact of Bioaerosols on indoor air qualityA growing concern. Advances in bioresearch 2(2): 120-123. 